\title{
1,2,4,5-Tetrahalogeno-Cyclohexanes and Structural Problems Related to Them
}

\author{
O. HASSEL, E. WANG LUND and K. L UNDE
}

Universitetets Kjemiske Institutt, Blindern - Oslo, Norway

havee members of the series of $1,2,4,5$ halogen substituted cyclohexanes
have been known for some time and the configurations of their molecules
determined. These are the tetrachloro-compound melting at $176^{\circ} \mathrm{C}$ and the
tetrabromo-compound of m.p. $187^{\circ} \mathrm{C}$, both having their halogen atoms in the
positions $1 \varepsilon, 2 \varepsilon, 4 \varkappa, 5 \varkappa^{1,2}$, and the tetrabromo-compound melting at $218^{\circ}$ in which all bromine atoms occupy $x$ positions ${ }^{3}$.

In the present communication a series of new substances will be described, some of which exhibit structural properties which seem to justify a more detailed description of the compounds.

All the substances were prepared from 1,4-cyclohexadiene by adding solutions of the appropriate halogens in an inert solvent to solutions of the diene, or in some cases of 1,2-dichlorocyclohexene(4) of m.p. $42^{\circ} \mathrm{C}$ which is formed in the first step of the addition reaction when a chlorine solution is added to the diene. In such cases the dichlorocyclohexene was first isolated and purified.

In the case of chlorine addition two different tetrachlorocyclohexanes were obtained, one of which is identical with the substance already mentioned of m.p. $176^{\circ} \mathrm{C}$. The second substance crystallizes from hot solutions in carbon tetrachloride in fine needles melting at $226^{\circ} \mathrm{C}$. When the solvent (ethyl acetate) was evaporated from solutions of the latter substance at room temperature, more compact crystals of a different habit were occasionally obtained. This new modification (the $\alpha$ modification) is stable at lower temperatures, the other modification ( $\beta$ modification) above $60-65^{\circ} \mathrm{C}$.

An exact determination of the transition point is difficult because of the low rate of transition at temperatures near this point. $\mathrm{X}$-ray photographs show that the $\beta$ modification is isomorphous with the tetrabromocyclohexane 
prepared by Wibaut and Haak ${ }^{3}$. However, the crystals so far examined are all twinned and built up of submicroscopical lamellae. The isomorphism just mentioned proves that in the molecules of the new 1,2,4,5-tetrachlorocyclohexane all chlorine atoms are in $x$ positions. It has subsequently been possible to prove that this holds true also for the molecules in the $\alpha$ modification (see below).

When bromine is added to the 1,2-dichlorocyclohexene(4) two different 1,2-dichloro-4,5-dibromocyclohexanes are also formed, one melting at $171^{\circ} \mathrm{C}$, the other at $240^{\circ} \mathrm{C}$. The latter turned out to be dimorphous giving an $a$ modification stable below $90-95^{\circ} \mathrm{C}$, and a $\beta$ modification stable at higher temperature. The $\beta$ modification is isomorphous with the $\beta$ modification of $1 x, 2 x$, $4 x$, $5 x$-tetrachlorocyclohexane and with the corresponding tetrabromocyclohexane prepared by Haak. The a modification, stable at lower temperatures, on the other hand, is isomorphous with the $a$ modification of the higher melting tetrachlorocyclohexane. This is obvious from $\mathrm{X}$-ray diagrams and even from the macroscopical properties of the crystals. Crystals of the $\beta$ modifications both of the tetrachlorocyclohexane and the dichloro-dibromocyclohexane may be kept at room temperature for a considerable length of time without showing any tendency to be transformed into the $a$ modification.

Table 1. Crystallographic data and calculated densities of $1 \varkappa, 2 \varkappa, 4 \varkappa, 5 \varkappa$-tetrahalogeno. cyclohexanes.

\begin{tabular}{|c|c|c|c|c|c|c|}
\hline & & $a$ & $b$ & $c$ & $\beta$ & Density \\
\hline $\mathrm{C}_{6} \mathrm{H}_{8} \mathrm{Cl}_{4}$ & $226^{\circ} \mathrm{C}$ & 6.13 & 6.74 & 10.72 & $97.8^{\circ}$ & 1.68 \\
\hline $\mathrm{C}_{6} \mathrm{H}_{8} \mathrm{Cl}_{2} \mathrm{Br}_{2}$ & $240^{\circ} \mathrm{C}$ & 6.29 & 6.93 & 10.81 & $98^{\circ}$ & 2.21 \\
\hline $\mathrm{C}_{6} \mathrm{H}_{8} \mathrm{Cl}_{4}$ & $226^{\circ} \mathrm{C}$ & 6.40 & 11.41 & 6.20 & $110^{\circ}$ & 1.73 \\
\hline $\mathrm{C}_{6} \mathrm{H}_{8} \mathrm{Cl}_{2} \mathrm{Br}_{2}$ & $240^{\circ} \mathrm{C}$ & 6.79 & 11.75 & 6.20 & $110^{\circ}$ & 2.22 \\
\hline $\mathrm{C}_{6} \mathrm{H}_{8} \mathrm{Br}_{4}$ & $218^{\circ} \mathrm{C}^{3}$ & 7.23 & 12.32 & 6.36 & $110.5^{\circ}$ & 2.49 \\
\hline
\end{tabular}

Table 1 contains the axial lengths and monoclinic angles of both forms of the higher melting tetrachloro- and dichloro-dibromocyclohexanes. The values reported by Haak have also been included for comparison. The densities calculated under the assumption that the unit cells all contain two molecules are in good agreement with those observed for other tetrahalogenocyclohexanes. The space group is $C_{2 h}{ }^{5}-P 2_{1} / c$ in all cases, from which follows that the molecules should have a point symmetry corresponding to a center of symmetry. This is of course in full agreement with the conclusion drawn above that the molecules have the $x, x, x, x$ configuration as long as the halogen atoms are all of the same kind. In the two modifications of 1,2-dichloro-4,5dibromocyclohexane, however, it would imply that the structures are of a 
disordered type. The molecules, although identical in shape, would have to be statistically orientated in space; positions occupied in some cases by chlorine atoms, would in other cases be occupied by bromine atoms. An analogous case was discussed in 1933 by Hendricks ${ }^{4}$ who found $p$-chloro-bromobenzene to be isomorphous with $p$-dichloro- and $p$-dibromobenzene, all substances crystallizing in the space group $P 2_{1} / c$ with two molecules in the unit cell. One of the present authors (E. W. L.) will publish a detailed report on the crystal structure work he has carried out on the two substances under discussion. So much may already be stated, however: Fourier projections of the $\alpha$ modification of the dichloro-dibromocyclohexane show halogen peaks which are all of the same height, and the distances from the center of the carbon ring to the halogen atoms are intermediate between the distances to be expected in the case of chlorine and bromine atoms.

The crystals of dichloro-dibromocyclohexane of m.p. $171^{\circ} \mathrm{C}$ were found to be isomorphous with the crystals of $1,2,4,5$-tetrachlorocyclohexane and tetrabromocyclohexane of m.p. $176^{\circ}$ and $187^{\circ} \mathrm{C}$ respectively, in which the halogen atoms are known to occupy the positions $1 \varepsilon, 2 \varepsilon, 4 \varkappa, 5 \varkappa$. As a matter of fact our main purpose when starting the work described in the present communication was to prepare the substance in question and to decide which of the two possible configurations of the molecule is the energetically more stable: that in which the chlorine atoms occupy $\varepsilon$ positions (Fig. la) or that in which they are in $x$ positions (Fig. 1b). This question has now been definitively settled on the basis of interferometric measurements using $\mathrm{X}$-ray crystallographic methods ${ }^{5}$ and also using the electron diffraction technique based on a rotating. sector $^{6}$. It was found that the chlorine atoms are in $\varepsilon$ positions, the bromine atoms in $\varkappa$ positions (Fig. la) both in the crystalline state and in the vapour. The explanation of this result seems rather straightforward: As pointed out already in $1943^{7}$ the distance from a chlorine or bromine atom in $\varepsilon$ position to the two nearest ( $\varepsilon$ bonded) hydrogen atoms in an undistorted structure is so small that a considerable repulsion must exist between them. This repulsion effect is likely to be greater in the case of a bromine atom than in the case of a chlorine atom. The repulsion between two $x$ halogen atoms attached to neighbouring carbon atoms will probably be of minor importance to the energy of the molecule than the halogen hydrogen interaction.

An observation which seems worth while mentioning regards the transformation of the higher melting isomer of 1,2-dichloro-4,5-dibromocyclohexane into the lower melting isomer. This transformation takes place to a considerable extent when the $240^{\circ}$ isomer is heated for some time above its melting point. As hydrogen halides are evolved during the process it is possible that the transformation involves a $S_{N_{2}}$ reaction. We have not, however, been able 


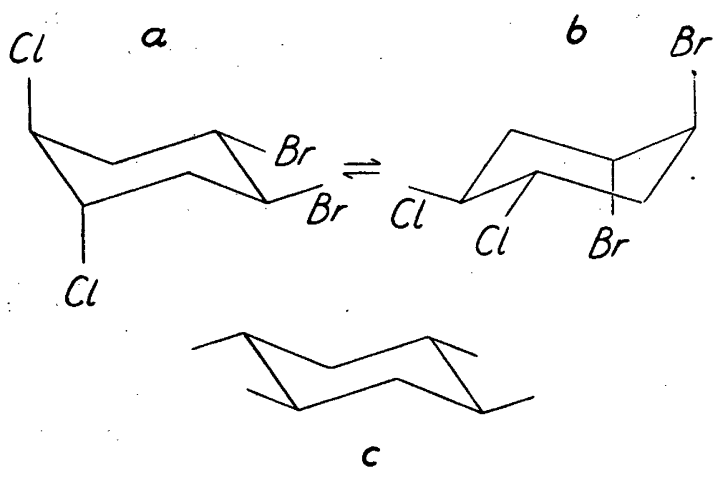

Fig. 1. a) and b). The two possible configurations of the 1,2-dichloro-4,5-dibromocyclohexane molecule (m.p. $\left.\left.171^{\circ} \mathrm{C}\right) . c\right)$ Molecular configuration of $1 \varkappa, 2 \varkappa, 4 \varkappa, 5 \varkappa$-tetrahalogenocyclohexane.

to perform a transformation at lower temperature by adding alkali halides to an alcoholic solution of the $240^{\circ}$ substance.

The melting point of $218^{\circ} \mathrm{C}$ reported by Wibaut and Haak for the $1 \varkappa$, $2 x, 4 x, 5 x$-tetrabromocyclohexane appears to be rather low when compared with the melting point of the corresponding crystals containing chlorine. It may be due to a decomposition similar to that observed in the case of the higher melting dichloro-dibromocyclohexane.

Iodo-monochloride reacts both with 1,4-cyclohexadiene and with 1,2dichlorocyclohexene(4). In the first case 1,4-dichloro-2,5-diiodocyclohexane (or 1,5-dichloro-2,4-diiodocyclohexane) of m.p. $121^{\circ} \mathrm{C}$ is formed, and in the second case 1,2,4-trichloro-5-iodo-cyclohexane having a melting point of $128^{\circ} \mathrm{C}$. If a solution containing equimolecular amounts of chlorine and bromine, after being exposed to light, contains appreciable quantities of bromo-monochloride as has occasionally been claimed ${ }^{8-10}$, one would expect it to react with the diene giving 1,4-dichloro-2,5-dibromocyclohexane (or 1,5-dichloro-2,4-dibromocyclohexane). However, we have not been able to obtain other products from the reaction than the dichloro-dibromo-cyclohexanes melting at $171^{\circ} \mathrm{C}$ and $240^{\circ} \mathrm{C}$ respectively. The reaction was carried out at low temperatures where the quantity of bromomonochloride present in the solution has been assumed to be considerable.

\section{EXPERIMENTAL}

1,2-Dichlorocyclohexene (4). Solutions in carbon tetrachloride containing 0.5 moles of 1,4-cyclohexadiene and 0.5 moles of chlorine respectively, were mixed at $0^{\circ} \mathrm{C}$. After evaporation of the solvent in vacuo the product was distilled at a pressure of $0.5 \mathrm{~mm}$. 
Nearly all the substance distilled at $45^{\circ} \mathrm{C}$. The crystal mass thus obtained was recrystallized from ethyl alcohol containing some water. M. p. $42^{\circ} \mathrm{C}$ :

$$
\begin{array}{llllllll}
\left(\mathrm{C}_{6} \mathrm{H}_{8} \mathrm{Cl}_{2}\right) & \text { Calc. } & \mathrm{C} & \mathbf{4 7 . 7 1} & \mathrm{H} & \mathbf{5 . 3 4} & \mathrm{Cl} & \mathbf{4 6 . 9 5} \\
& \text { Found } & \text { " } & 47.58 & " & 5.50 & " & \mathbf{4 6 . 6 5}
\end{array}
$$

1,2,4,5-Tetrachlorocyclohexanes. To a solution of 0.1 moles of 1,2-dichlorocyclohexene(4) (m.p. $42^{\circ} \mathrm{C}$ ) in carbon tetrachloride a solution of 0.1 moles of chlorine in the same solvent was added at $0^{\circ} \mathrm{C}$. Some crystals were deposited and isolated (m.p. $226^{\circ} \mathrm{C}$ ). The solid substance remaining after evaporation of the carbon tetrachloride from the solution was separated into its two components by alternating crystallization from carbon tetrachloride and ethyl acetate. Besides further quantities of the substance melting at $226^{\circ} \mathrm{C}$ and crystallizing in fine needles appreciable quantities of 1,2,4,5-tetrachlorocyclohexane of m.p. $176^{\circ} \mathrm{C}$ were obtained. The higher melting compound is also a tetrachlorocyclohexane:

$$
\begin{array}{llll}
\left(\mathrm{C}_{6} \mathrm{H}_{8} \mathrm{Cl}_{4}\right) & \text { Calc. } & \mathrm{Cl} & 63.89 \\
& \text { Found } & \text { " } & 63.45
\end{array}
$$

1,2-Dichloro-4,5-dibromocyclohexanes. When bromine (0.1 moles) was added to dichlorocyclohexene of m.p. $42^{\circ} \mathrm{C}(0.1 \mathrm{moles})$ under the conditions just described in the case of chlorine, crystals were also deposited. Further crystals were obtained from the remaining liquid on evaporation of the carbon tetrachloride. The same technique as described in the case of the tetrachloro-compounds was used in order to separate the two substances formed in the addition reaction. In this case also, the higher melting substance - m.p. $240^{\circ}$-formed thin needle-shaped crystals, whereas the crystals of the lower melting substance - m.p. $171^{\circ} \mathrm{C}$ - were rather compact and some times they were obtained in the form of twins forming regularly shaped crosses (Fig. 2). The melting point $240^{\circ} \mathrm{C}$ for the higher melting compound is only obtained by rapid heating, in other cases a lower value is found, probably as a result of beginning decomposition.

$$
\begin{aligned}
& \left(\mathrm{C}_{6} \mathrm{H}_{8} \mathrm{Cl}_{2} \mathrm{Br}_{2}-240^{\circ} \mathrm{C}\right) \quad \text { Found } \mathrm{Cl} 23.19 \mathrm{Br} 50.75 \\
& \left(\mathrm{C}_{6} \mathrm{H}_{8} \mathrm{Cl}_{2} \mathrm{Br}_{2}-171^{\circ} \mathrm{C}\right) \quad \text { Found } \quad \mathrm{Cl} 21.85 \text { Br } 51.92 \text { Mol.w. Found } 305 \\
& \text { Calc. "22.81 "51.41 " Calc. } 311
\end{aligned}
$$

Dichloro-diiodocyclohexane. To 0.2 moles of 1,4-cyclohexadiene dissolved in $200 \mathrm{ml}$ of ethyl ether was added a solution of $65 \mathrm{~g}$ of iodo-monochloride dissolved in ethyl ether, the temperature being kept below room temperature. After some hours considerable quantities of crystals had been deposited. The crystals were washed with pure solvent and recrystallized from chloroform. They were well-developed rhombic plates of m.p. $121^{\circ} \mathrm{C}$ :

$$
\begin{array}{llllll}
\left(\mathrm{C}_{6} \mathrm{H}_{8} \mathrm{Cl}_{2} \mathrm{~J}_{2}\right) & \text { Calc. } & \mathrm{Cl} & 17.52 & \mathrm{I} & 62.70 \\
& \text { Found } & 17.15 & & 63.20
\end{array}
$$

Trichloro-idodocyclohexane. To 0.01 moles of dichlorocyclohexene (m.p. $42^{\circ} \mathrm{C}$ ) dissolved in ethyl ether an etheric solution of 0.01 moles of iodo-monochloride was added. After a few days the solvent was evaporated and the crystal mass thus obtained recrystallized from alcohol containing some water. Needle-formed crystals were obtained melting at $128^{\circ} \mathrm{C}$ :

$$
\begin{array}{llllll}
\left(\mathrm{C}_{6} \mathrm{H}_{8} \mathrm{Cl}_{3} \mathrm{~J}\right) & \text { Calc. } & \mathrm{Cl} & \mathbf{3 3 . 9 5} & \mathrm{I} & \mathbf{4 0 . 4 9} \\
& \text { Found } & \text { " } & \mathbf{3 4 . 0 5} & \text { " } & \mathbf{4 0 . 3 4}
\end{array}
$$

Transition phenomena. In order to decide which of the two modifications of the higher melting dichloro-dibromocyclohexane is stable at room temperature, a mixture containing both $\alpha$ and $\beta$ crystals was kept in contact with a saturated solution in ethyl acetate 
Fig. 2. Twin crystals of 1,2-dichloro-4,5dibromocyclohexane, m. p. $171^{\circ} \mathrm{C}$.

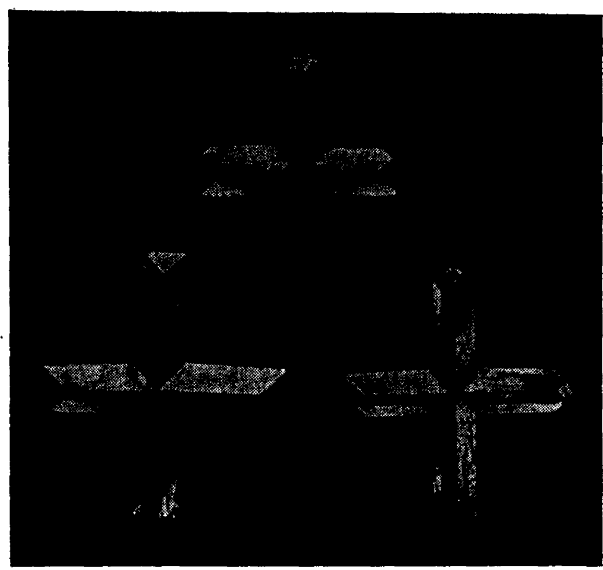

for some days. Growth of the $\alpha$ crystals at the expense of $\beta$ crystals was then observed. At temperatures above $120^{\circ} \mathrm{C}$ the transition of $\alpha$ crystals into $\beta$ crystals takes place at a considerable rate. A more exact determination of the transition point could be carried out by keeping crystals for a considerable time at temperatures varying between $90^{\circ}$ and $110^{\circ} \mathrm{C}$. It was found that the transition temperature lies between $90^{\circ}$ and $95^{\circ} \mathrm{C}$.

Using the same procedure the transition temperature for the higher melting tetrachloro-compound was found to lie between the limits $60^{\circ}$ and $65^{\circ} \mathrm{C}$, the $\alpha$ modification being the form stable at lower temperatures.

\section{SUMMARY}

The following substances have been prepared from 1,4-cyclohexadiene and chlorine, bromine or iodo-monochloride:

1,2-dichlorocyclohexene(4), m.p. $42^{\circ} \mathrm{C}$

1,2,4,5-tetrachlorocyclohexane, m.p. $226^{\circ} \mathrm{C}$

1,2,4,5-tetrachlorocyclohexane, m.p. $176^{\circ} \mathrm{C}$

1,2-dichloro-4,5-dibromocyclohexane, m.p. $240^{\circ} \mathrm{C}$

1,2-dichloro-4,5-dibromocyclohexane, m.p. $171^{\circ} \mathrm{C}$

1,2,4-trichloro-5-iodocyclohexane, m.p. $128^{\circ} \mathrm{C}$

dichloro-diiodocyclohexane, m.p. $121^{\circ} \mathrm{C}$

In the 1,2-dichloro-4,5-dibromocyclohexane of m.p. $171^{\circ} \mathrm{C}$ the chlorine atoms occupy $\varepsilon$ positions, the bromine atoms $\varkappa$ positions. Even in the gaseous state no indications of the inverted form with chlorine in $\varkappa$ positions, bromine in $\varepsilon$ positions could be detected. An explanation of this observation is given. The $1 x, 2 x$-dichloro- $4 x$, 5x-dibromocyclohexane (m.p. $240^{\circ}$ ) is dimorphous, the higher temperature form $(\beta)$ is isomorphous with the tetrabromocyclo- 
hexane prepared by Haak. Both forms, however, crystallize in the space group $\mathrm{P2}_{1} / \mathrm{c}$ with two molecules in the unit cell which would require the molecule to have a center of symmetry. It must be assumed, therefore, that the molecules are statistically orientated in the crystal. In the case of the low temperature form $(\alpha)$ the correctness of this conclusion has been substantiated by the working out of electron density maps of the structure.

\section{REFERENCES}

1. Hassel, O., and Wang Lund, E. Acta Chem. Scand. 3 (1949) 203; Acta Cryst. 2 (1949) 309.

2. Halmøy, E., and Hassel, O. J. Am. Chem. Soc. 61 (1939) 1601.

3. Haak, F. A., and Wibaut, J. P. Recueil 67 (1948) 85.

Haak, F. A. Dissertation (1948). Amsterdam.

4. Hendricks, St. B. Z. Krist. 84 (1933) 85.

5. Hassel, O., and Wang Lund, E. Acta Chem. Scand. 6 (1952) 238.

6. Bastiansen, O., and Hassel, O. Acta Chem. Scand. 5 (1951) 1404.

7. Hassel, O., and Viervoll, H. Tidsskr. Kjemi Bergv. Met. 3 (1943) 35.

8. Hanson, N. W., and James, T. C. J. Chem. Soc. (1928) 1955.

9. Hanson, N. W., and James, T. C. J. Chem. Soc. (1928) 2979.

10. Forscey, L. A., and Taylor, T. W. S. J. Chem. Soc. (1930) 2272. 